\title{
Justifying the productivity of a grain dryer in the climate of the Southern Urals
}

\author{
Sergey Shepelev ${ }^{1, *}$, Dmitry Vnukov ${ }^{1}$, Vladimir Chumakov ${ }^{2}$, Oleg Polushkin ${ }^{3}$, Viacheslav \\ Lebedenko $^{3}$, Svetlana Ponomareva ${ }^{3}$ \\ ${ }^{1}$ South Ural State Agrarian University, Russia, 454080, Chelyabinsk region, Chelyabinsk, Lenin \\ Avenue, 75 \\ ${ }^{2}$ Kurgan State Agricultural Academy by T.S. Maltsev, Russia, 454080, 641300, Kurgan region, \\ Ketovsky district, Lesnikovo village \\ ${ }^{3}$ Don State Technical University, Gagarin sq., 1, 344000, Rostov-on-Don, Russia
}

\begin{abstract}
The use of grain-drying complexes is established to make possible to start harvesting before the crops are fully ripened, to shorten the harvesting period, to increase the productivity of combine harvesters and reduce production losses. An economic and mathematical model is developed to justify the productivity of grain-drying equipment, taking into account the rate of grain supplied from the field. Simulation made possible to reveal the rational productivity of a grain dryer taking into account a wide range of natural and production factors. The dependence of the operation of combine harvesters on the moisture content of the grain mass is obtained. It is established that the use of crops with different growing periods in crop rotation makes possible to expand the rational range of harvesting equipment and grain-cleaning complexes, to reduce the total cost of production.
\end{abstract}

\section{Introduction}

To ensure the food security of the Russian Federation, it is necessary to provide timely harvesting and grain safety. After the complete ripening of crops, productivity is known to decrease significantly [1] when harvesting time increases. The harvesting rate and the grain amounts are significantly dependent on the seasonal load of grain-harvesting equipment $[2$, $3]$. In $[4,5]$ it is indicated that the timeliness of field works largely depends on the seasonal load of technical means. The problem of the harvesting campaign is worsened by climatic conditions $[6,7]$. Weather conditions being random by nature complicate the process of harvesting and drying grain. The work [8] presents a simulation model for controlling the grain-drying system, with the type of fuel used being taken into account. The effect of moisture in wheat on the need for productivity of the harvesting-transporting line and graindrying complexes is examined in detail in $[9,10]$

\footnotetext{
* Corresponding author: shepelev2@yandex.ru
} 


\section{Main part}

Thus, material and labor resources being short, a decrease in the rate of harvesting due to the high moisture content of the grain significantly prolongs the harvesting period and increases crop losses. Grain-drying equipment available in farms makes possible to start the harvesting earlier and not to stand idle because of the high grain moisture caused by precipitation. However, when designing grain-drying complexes, it is necessary to take into account their cost, grain yield, quantitative and qualitative conditions of harvesting and weather conditions.

To justify the rational performance of grain-drying equipment, depending on weather conditions, an objective function has been developed based on the minimum cost:

$$
U_{m . c}=Z_{f}+L+Z_{d . e} \rightarrow \min ,
$$

where $Z_{f}$ is the costs of fuel necessary for drying, RUB/ha; Listhe production losses dependent on the harvesting period, RUB/ha; $Z_{d . e}$ is the costs for purchasing the grain-drying equipment, RUB/ha.

The costs of fuel necessary for drying grain is found by the formula:

$$
Z_{f}=\frac{Q_{h} D_{d} \tau_{d} R_{t} F D_{h . p}}{Q}
$$

where $Q_{h}$ is the hourly productivity of grain-drying equipment, $\mathrm{t} / \mathrm{h} ; D_{d}$ is the dryer operating time during the day, $\mathrm{h} ; \tau_{d}$ is the coefficient of the dryer useful time; $R_{t}$ is the amount of fuel spent on drying 1 ton of grain, $1 ; F$ is the cost of one liter of fuel, RUB; $D_{h . p}$ is the number of days within the harvesting period, days; $Q$ is the harvested area of crops, ha.

The damage from product losses when using grain-drying equipment is determined by the formula:

$$
L=0.5 K_{r . l} k_{l} Y V \frac{Q K_{g}}{n H_{d} P_{x}}+0.5 K_{r . l} k_{l} Y V \frac{Q\left(1-K_{g}\right)}{n H_{d} P_{x 1} K}
$$

where $K_{r l}$ is the coefficient of reducing the losses due to combining varieties, crops according to earliness; $k_{l}$ is the loss factor, portion/day; $V$ is the production value, RUB/t; $Y$ is the yield, t/ha; $n$ is the number of combine harvesters, pcs.; $H_{d}$ is the harvester operating time during the day, $\mathrm{h} ; K$ is the proportionality coefficient; $P_{x}$ is the productivity of a combine harvester, ha/h; $P_{x I}$ is the productivity of the combine harvester depending on the moisture content of the grain mass, ha/h; $K_{g}$ is the coefficient of grain portion supplied for drying out of the total volume.

It should be noted that the productivity of the harvesting unit is mostly dependent on the moisture content of the grain mass. The condition of the grain mass is determined mainly by the precipitation amount, temperature and humidity. We have obtained regression equations describing the changes of the combine harvester productivity caused by the moisture content of the grain mass:

$$
P_{x l}=-0,1901 V_{g}+7,2026
$$

Where $V_{g}$ is the moisture content of the grain mass, $\%$.

According to the statistical data, the factor of weather conditions during the harvesting period is revealed, which is 0.9 when the weather conditions are favorable, 0.45 and 0.38 when the weather conditions are normal and unfavorable, respectively. 
According to the statistical data, the coefficient of the grain portion out of the total amount supplied for drying is determined by the formula:

$$
K_{g}=\frac{Q_{g}-Q_{g 1}}{Q_{g}}
$$

where $Q_{g}$ is the total area for grain crops, ha; $Q_{g l}$ is the area for grain crops with high moisture content.

The dependence of the costs of operating grain-drying equipment is determined from the expression:

$$
Z_{d e}=\frac{B_{d}\left(Q_{h}\right) \alpha}{Q}
$$

Where $B_{d}\left(Q_{h}\right)$ is the balance price of the grain dryer depending on its productivity, RUB; ais the allowance for depreciation.

The coefficient limiting the productivity of the harvesting-transporting line $\left(K_{p r}\right)$ with the grain dryer productivity is determined by the formula:

$$
\mathrm{K}_{p r}=\frac{\frac{Q_{h}}{K_{m}} D_{d} \tau_{d}}{n H_{d} P_{x}}
$$

Where $Q_{h}$ is the productivity of the grain-drying complex, $\mathrm{t} / \mathrm{h} ; K_{m}$ is the coefficient of grain moisture.

In general, the objective function (1) can be represented as:

$$
\begin{aligned}
& \mathrm{U}_{\mathrm{m} . \mathrm{c}}=\frac{B_{d}\left(Q_{h}\right) \alpha}{Q}+0.5 \mathrm{~K}_{\mathrm{r} . \mathrm{l}} k_{l} Y V \frac{Q K_{g}}{n H_{d} P_{x}}+0.5 \mathrm{~K}_{\mathrm{r} .1} Y k_{l} V \frac{Q\left(1-K_{g}\right)}{\frac{Q_{h}}{K_{m} \tau_{d}}}+ \\
& +\frac{Q_{h} D_{d} \tau_{d} R_{t} F D_{h} \frac{P_{h} p}{n H_{d} P_{x}}}{Q} \rightarrow \min
\end{aligned}
$$

The expression 8 after conversion will take the form:

$$
\begin{aligned}
& \mathrm{U}_{\mathrm{m} . \mathrm{c}}=\frac{B_{d}\left(Q_{h}\right) \alpha}{Q}+\frac{V K_{r l} Q Y k_{l} 0.5\left(K_{m} H_{d} P_{x}^{2} n-K_{m} K_{g} H_{d} P_{x}^{2} n+K_{g} Q_{h} H_{d} P_{x 1} \tau_{d}\right)}{Q_{h} D_{d} H_{d} P_{x} P_{x 1} n \tau_{d}} \\
& +\frac{Q_{h} D_{d} \tau_{d} R_{t} F D_{h \cdot p}}{Q} \rightarrow \mathrm{min}
\end{aligned}
$$

The relationship between the grain dryer productivity and the volume of grain supplied for drying is determined due to the simulation (Figure 2). 


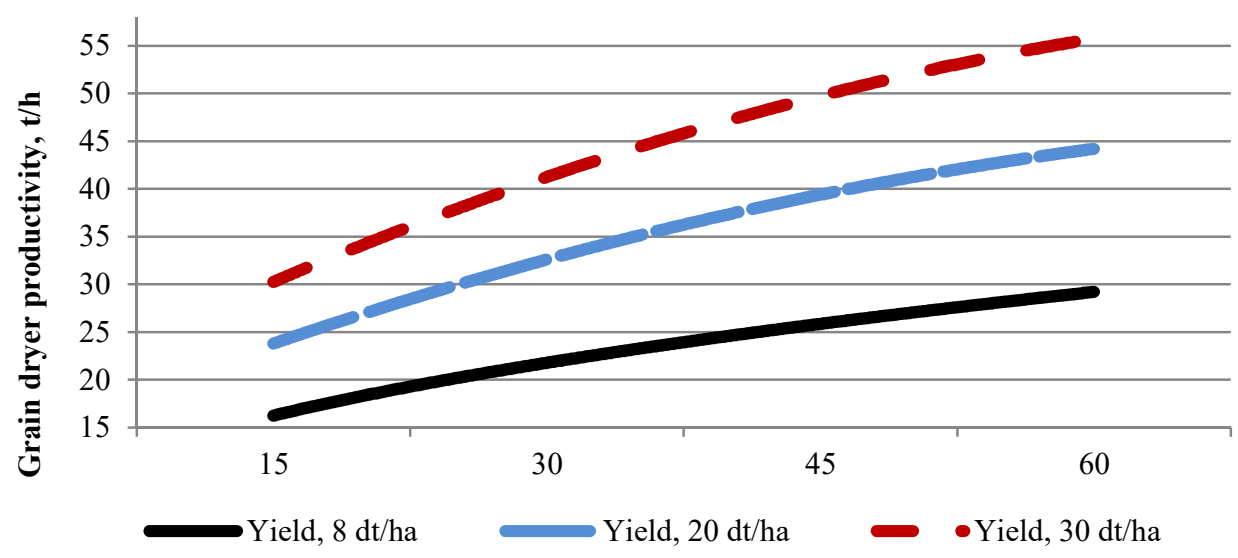

The grain portion out of the total amount supplied for drying, $\%$

Fig. 1 - The grain dryer productivity dependent on the yield with different volumes of grain supplied for drying (at $Q_{g}=18000 \mathrm{ha} ; \tau_{h}=0.55$ (the coefficient of the harvester useful time); $V_{h}=7 \mathrm{~km} / \mathrm{h}$ (the harvester speed); $W_{h}=7 \mathrm{~m}$ (the harvester header width); $M_{g}=20 \% ; n=18 \mathrm{pcs}$.)

With the amount of wet grain and the yield increasing, the design productivity rises. It is established that under unfavorable weather conditions when grain drying is required to exceed $50 \%$ of the total volume, with the yield being $20 \mathrm{dt} /$ ha, the productivity of the graindrying complex should be at least $45 \mathrm{t} / \mathrm{h}$.

To increase the efficiency of agricultural production is possible by expanding the time of using of grain harvesting equipment because of crops and varieties with different growing periods, such as durum and soft wheat, barley, oats, rye, peas, sunflowers and other crops in crop rotation (Figure 3).

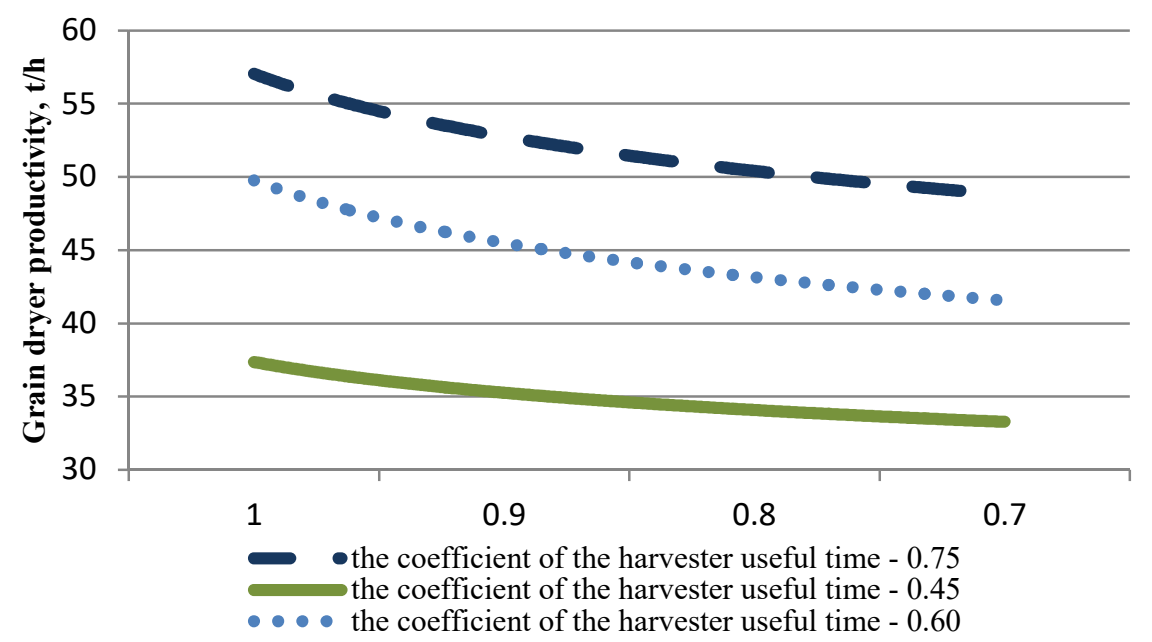

The coefficient of reduced losses caused by wheat falling when using combinations of crops in crop rotation 
Fig. 2 -The grain dryer productivity depending on the combination of crops in crop rotation for different $\tau$ of the harvester (at $Q_{g}=18000$ ha; $Y=20 \mathrm{~kg} / \mathrm{ha} ; V_{h}=7 \mathrm{~km} / \mathrm{h} ; W_{h}=7 \mathrm{~m} ; M_{g}=20 \% ; n=18$ pcs. $K_{g}=30 \%$ )

The figure shows that the combination of crops with different growing periods, has a significant impact on the grain dryer productivity, with the productivity of the combine harvester being taken into account. When reducing the coefficient to take into account the use of early varieties (the crops from the range 1-0.7), the rational productivity with the coefficient of the useful time of a combine harvester is 0.6 , decreases from 50 to $40 \mathrm{t} / \mathrm{h}$.

The increasing of the coefficient of useful time of the combine harvester from 0.45 to 0.6 rises the productivity of the grain dryer up to $20 \%$.

When justifying the rational productivity of grain-drying equipment, it is necessary to take into account the coefficient of useful time. Figure 4 shows the results of timing observed while the grain-drying complex was in operation.

When the MEPU grain-drying complex was in operation, $17 \%$ of the shift time was spent on loading the tanker with wet grain, $5 \%$ of the shift time was spent on technological failures, $3 \%$ of the shift time was spent on downtime due to technical failures and $5 \%$ of downtime was caused by waiting for grain. The average rate of using the day time for the MEPU grain-drying complex was 0.65 .

It is possible to increase the operating time of the grain-drying complex due to grain inputting and cleaning of impurities with the help of grain-cleaning machines.

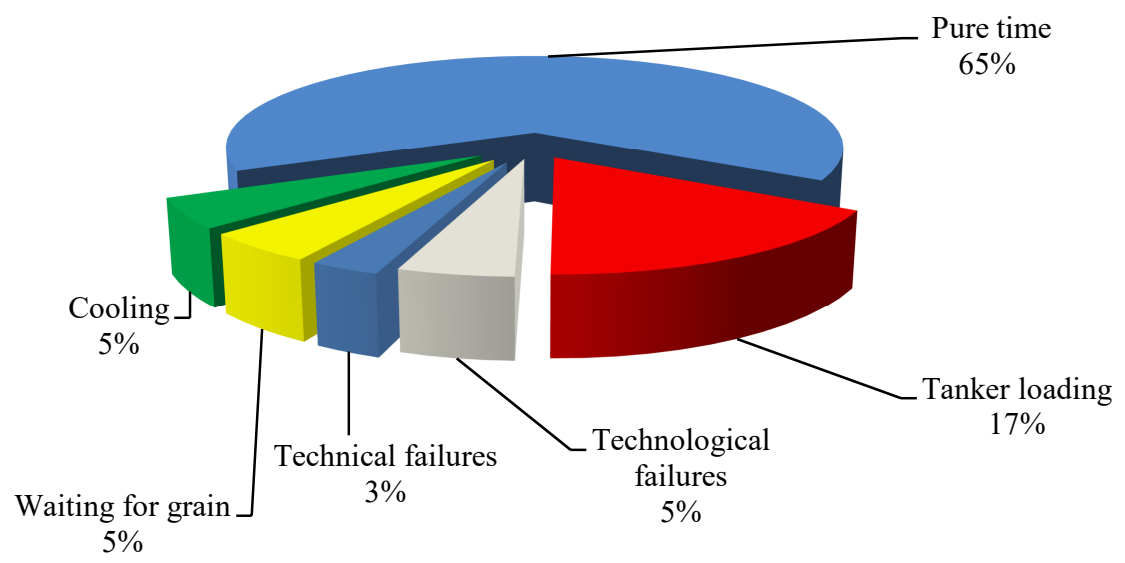

Fig. 3 - Time structure of a grain drying complex

\section{Findings}

It has been established that therelevant dependence of operating combine harvesters on weather conditions, the moisture content of the grain mass causes significant fluctuations in the rate of grain supplying influencing the process and prolongations of harvesting.

Thus, to justify the rational productivity of a grain drying complex, a methodology based on economic and mathematical modeling is developed, with the rate of grain input in the climate of the Southern Urals being taken into account. 


\section{References}

1. K. Shinners, G. Boettcher, D. Hoffman, J. Munk, R. Muck, \& P. Weimer, Transactions of the ASABE, 52, 51-60 (2009)

2. S. Shepelev, V. Shepelev, Z. Almetova, N. Shepeleva, M. Cheskidov, IOP Conference Series: Earth and Environmental Science, 115 (2018)

3. S. Shepelev,V. Shepelev, Z. Almetova, Procedia Engineering, 150, 1258-1262 (2016)

4. S. Shepelev, V. Shepelev, Yu. Cherkasov, ProcediaEngineering, 129, 161-165 (2015)

5. M. Mubayiwa, B. Mvumi, T. Stathers, S. Mlambo, T. Nyabako, Crop protection, 109, 51-61 (2018)

6. De Toro, C. Gunnarsson, G. Lundin, N. Jonsson, Biosystems Engineering, 111, 429439 (2012)

7. N. Nawi, G. Chen, \& D. Zare, Biosystems Engineering, 106, 493-502 (2010)

8. J. Schemminger, D. Mbuge, W. Hofacker, Thermal Science and Engineering Progress. 13 (2019)

9. A.N. Vasilyev, A.A. Vasilyev, International Russian Automation Conference, RusAutoCon, 2018 (2018)

10. M. Wold, M. Kocher, D. Keshwani, \&D. Jones, Paper presented at the American Society of Agricultural and Biological Engineers Annual International Meeting 2011, ASABE 2011, 68-86 (2011) 